\title{
Surface Wind System Forecasting by the Principal Component Autoregressive Model
}

\author{
By Hirokazu Kobayashi and Shaw Nishinomiya
}

\author{
Central Research Institute of Electric Power Industry, 11-1, Iwato-kita, 2-chome Komae-shi, Tokyo 201 \\ (Manuscript received 26 June 1985, in revised form 15 February 1986)
}

\begin{abstract}
A statistical forecasting method for the surface wind system was developed for the purpose of predicting the behavior and evaluating the effects of pollutants released to the atmosphere near the surface. The surface wind system represented by data from many stations can be considered to be subject to larger scale atmospheric motion, even if the observed wind data show some discrepancies with each other. The wind system is forecasted by the following method. First, the principal components of surface wind system fluctuation are extracted using principal component analysis. Next, the future principal components are forecasted from time series of these principal components using autoregressive equations by applying the maximum entropy method. The future values of the wind system are then obtained. This method was applied to the Kanto Plain using AMeDAS wind data. Forecast time of 1, 3, 6 and 12 hours were selected. A comparison of this method with persistence forecasting method shows that this method gives better results for each forecasting period.
\end{abstract}

\section{Introduction}

When pollutants that produce adverse effects on the environment are released to the atmosphere, it is necessary to forecast the advection and the diffusion of the pollutants in order to take proper countermeasures. The behavior of pollutants is determined to a considerable extent by the conditions of surface wind system when the source of pollutants is near the ground surface. It is thus necessary to forecast surface wind as the first step in forecasting pollutant behavior. Wind system forecasting methods may be divided into those using dynamic models and those using statistical models. Because the wind near the ground surface is significantly affected by the surface roughness or the terrain, the statistical forecasting method is sometimes superior to the dynamic modeling method when the surface conditions of the forecast region are relatively complex. Hirose (1977) proposed a wind system forecasting method based on principal component analysis (PCA). The present authors developed this method and made a wind system fore- casting model combining principal component analysis and autoregressive equations using the maximum entropy method (WSPCAR; Wind System Forecasting by the Principal Component Autoregressive Model).

\section{Wind system forecasting model}

It was assumed that the surface wind system was given by wind speed and direction data observed at many stations. Generally the surface wind system within a certain time and space scale is subject to larger scale atmospheric motion. On the other hand, the wind observed at each station is affected by the local topography. Thus the observed wind data have some correlation with the total wind system but often diverge. Considering this characteristic of the surface wind system, the forecasting model was constructed from the following two parts.

(1) The wind $\xi_{i}$ observed at each station was represented by the linear combination of $\psi_{0}, \psi_{1}, \ldots, \psi_{n}$ that were parameters extracted from the total wind system. The 
parameters were treated independently of each other.

(2) Next, by forecasting the parameters $\psi_{k}$ $(k=0, \ldots, n)$ by a proper method, $\xi_{i}$ could be forecasted using the equation of $\xi_{i}$ and $\psi_{k}$ of part (1).

Using this idea, the surface wind system forecasting model was developed. The part (1) was performed by employing principal component analysis and the part (2) by autoregressive equations using the maximum entropy method.

\subsection{Application of principal component analy- sis}

Principal component analysis (PCA) or empirical orthogonal function has been applied frequently for the statistical analysis of meteorological data. Estimation of precipitation (Stidd, 1967) was one of the early applications. Akiyama (1981) used this method for the temporal and spatial variation of snowfalls in a coastal region. Principal component analysis can extract characteristics of whole variables that are correlated, as independent principal components. When observed wind data $x_{p}$ as measured at $p$ stations, the $m$ ( $m \leqq p)$ principal components $Y_{m}$ (i.e., principal components; first, second, $\ldots, m^{\prime}$ th) are defined as follows.

$$
Y_{k}=\sum_{i=1}^{p} l_{k i} x_{i} \quad(k=1,2, \cdots, m),
$$

where $\ell_{k}$ is the eigenvector and

$$
\sum_{i=1}^{p} l_{k i}{ }^{2}=1 \quad(k=1,2, \cdots, m) .
$$

Conversely, each variable can be estimated with principal components $Y_{1}, Y_{2}, \ldots, Y_{m}$ and eigenvector $\ell_{k i}(k=1,2, \ldots, m ; i=1,2, \ldots$, $p)$, under the condition that $m<p$. When the estimated variable of $x$ is represented as $X$, the relationship can be described as follows,

$$
X_{i}=\sum_{k=1}^{m} l_{k i} Y_{k} \quad(i=1,2, \cdots, p) .
$$

These relations can be used for constructing the forecasting model. If eigenvector $\ell_{k i}$ nearly invariant during $\Delta t$ which is very small compared to $T$ which was the time period for $\ell_{k i}$ to be evaluated, the future surface wind system $\xi(t+$ evaluated, the future surface wind system $\xi(t+\Delta t)$ at time $t+\Delta t$ can be represented by Eq. (3). Then by obtaining the forecasted $Y$ at the
$\xi(t+\Delta t)$ can be calculated. As mentioned previously, principal components are independent of each other, so the time series of the principal components are also independent. It is suggested that the prediction of $Y$ be performed using only the time series of $Y$ itself.

It would be suitable to use the vectorized PCA because the wind is a vector. Hardy and Walton (1978) studied a wind system representing the wind which speed was $\mathrm{u}$ and direction was $\theta$ by the complex number $\sigma=u e^{i \theta}$, and applying the eigenvector analysis for the complex matrix. However, the present paper takes the traditional but simple approach in which the vector wind is decomposed into two components and the scalar method is used for the combining of the wind forecasting program into the real-time computer system. Wind data for the forecasting model are normalized as follows. Primarily, the wind data at i'th station for each observed time $t$ were decomposed into eastwest and south-north components $u(i, t)$ and $v(i, t)$, and the mean values of the components $\overline{u(i)}$ and $\overline{v(i)}$ were calculated for some duration $T$. Simultaneously, the mean wind speed of whole observed data $\bar{U}$ was calculated for the duration $T$. Finally, $u$ and $v$ are normalized by the next equations,

$$
\begin{aligned}
& u^{\prime}(i, t)=\{u(i, t)-\overline{u(i)}\} / \bar{U} \\
& v^{\prime}(i, t)=\{v(i, t)-\overline{v(i)}\} / \bar{U} \\
&(i=1,2, \cdots, p) .
\end{aligned}
$$

Then $u^{\prime}$ and $v^{\prime}$ are redefined as $w$,

$$
\begin{aligned}
& w(2 i-1, t)=u^{\prime}(i, t) \\
& w(2 i, t)=v^{\prime}(i, t) \quad(i=1,2, \cdots, p) .
\end{aligned}
$$

Using PCA, the eigenvectors are obtained from $w(j, t)(j=1,2, \ldots, 2 p)$.

\subsection{Applying autoregressive equations to the principal component series}

Forecasting the principal components is facilitated by applying autoregressive equations to time series of the principal components. When the principal component of the wind system is $Y(t, k)(k=1,2, \ldots, m)$, the future value $\hat{Y}(t+\Delta t, k)$ at the time $t+\Delta t$ is generally forecasted by the following equation, 


$$
\begin{array}{r}
\hat{Y}(t+\Delta t, k)=\sum_{j=1}^{n} a_{j} Y(t-(j-1) \Delta t, k) \\
(k=1,2, \cdots, m) .
\end{array}
$$

Akaike (1969a, b) showed that applying the autoregressive equation represented above is equivalent to estimating the power spectrum of the time series. He widened the scope of the forecasting method by using autoregressive equation. This estimation of the power spectrum is well known maximum entropy method (MEM) which is a superior method of spectral analysis for obtaining stable results from nearly random time series such as time series of wind data. Presently, MEM is well accepted as one method of spectral analysis, but, there are few examples of applications for the meteorological forecast. The coefficients, $a_{1}, a_{2}, \ldots, a_{n}$ are calculated by MEM using Burg's technique (Anderson, 1974) and the number of terms, $n$, is given by the number of terms for which the final prediction error (FPE) has the lowest value (Ulrych and Bishop, 1975). FPE is defined as follows,

$$
\begin{aligned}
F P E_{n}= & \frac{N+(n+1)}{N-(n+1)} \sum_{j=n+1}^{N}\{Y(t-j \Delta t, k) \\
& -a_{n 1} Y(t-(j-1) \Delta t, k) \cdots \\
& \left.-a_{n n} Y(t-(j-n) \Delta t, k)\right\}^{2},
\end{aligned}
$$

where $a_{n \ell}$ shows the $\ell$-th coefficient of the result calculated up to the $n$-th term and $N$ is the length of the series of $Y$.

\section{Forecasting the surface wind system}

With the Kanto Plain as the forecasting area, the surface wind system was forecasted. Primarily, the wind data of two summer months from Jul. to Aug. of 1981 were selected. During that period, it was supposed that prevailing winds such as the winter northwesterly monsoon did not blow. If the data in winter are selected, the wind directions would mostly range within a few points of compass. Consequently the forecasted winds would comparatively agree better with the observed winds than cases of other seasons. However, it would be relatively difficult to evaluate the performance of the forecasting methods from a winter case.

Hourly surface wind data were extracted from the 32 AMeDAS stations in the southern area of the Kanto Plain. The sampling duration $T$ for calculating eigenvectors was set that $T=1$ week considering the time scale of the meteorological perturbation of forecasting area. Therefore, the number of data points was 168 per statiion. PCA was performed for each data set and the winds 1 -hour in the future are forecasted by analyzing the time series usig MEM. Forecasts were made for each hour, that is, PCA for a week retroactively and MEM analysis was performed for each hour through the subject period. Forecasting times $\Delta t$ were set such that $\Delta t=1,3,6$ and $12 \mathrm{hrs}$. In the case of forecasting for $\Delta t$ that was greater than 1 hour was realized by simply using the coefficients of the autoregressive equation derived for $\Delta t=1$ hour and the forecasted values, e.g., the principal component $\hat{Y}^{\prime \prime}$ at 2 hours later was obtained as follows,

$$
\hat{Y}^{\prime \prime}=a_{1} \hat{Y}^{\prime}+a_{2} Y(t, k)+a_{3} Y(t-\Delta t, k) \cdots,
$$

where $\hat{Y}^{\prime}$ is the principal component derived for $\Delta t=1$ hour. In Eq. (7) of section 2, it was shown that the number of terms of the autoregressive equation varied by the condition of time series of principal components and the number was mostly 2 to 5 in summer. Figure 1 shows an example of time series of the first, second, third, fifth and tenth principal components and their forecasts.

Next, the forecasted wind systems were presented that were obtained from the fore-

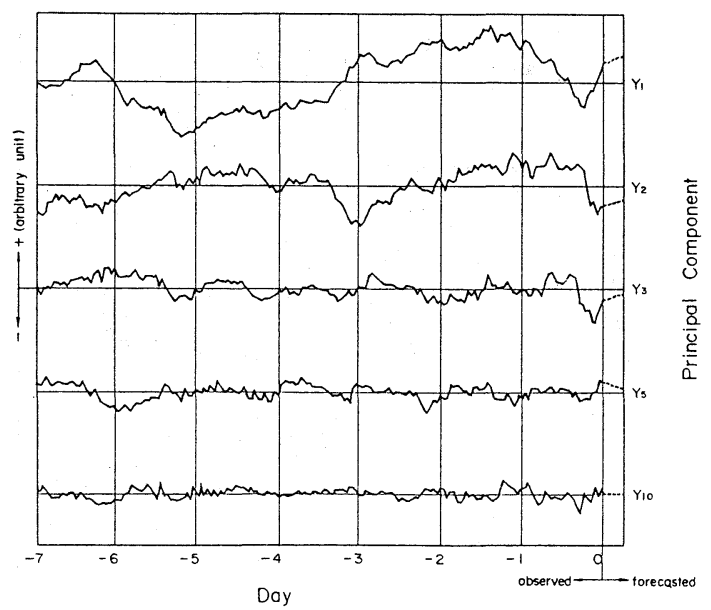

Fig. 1. Time series of the first, second, third, fifth and tenth (for each $Y_{1}, Y_{2}, Y_{3}, Y_{5}$ and $Y_{10}$ ) principal components and their forecasts. 

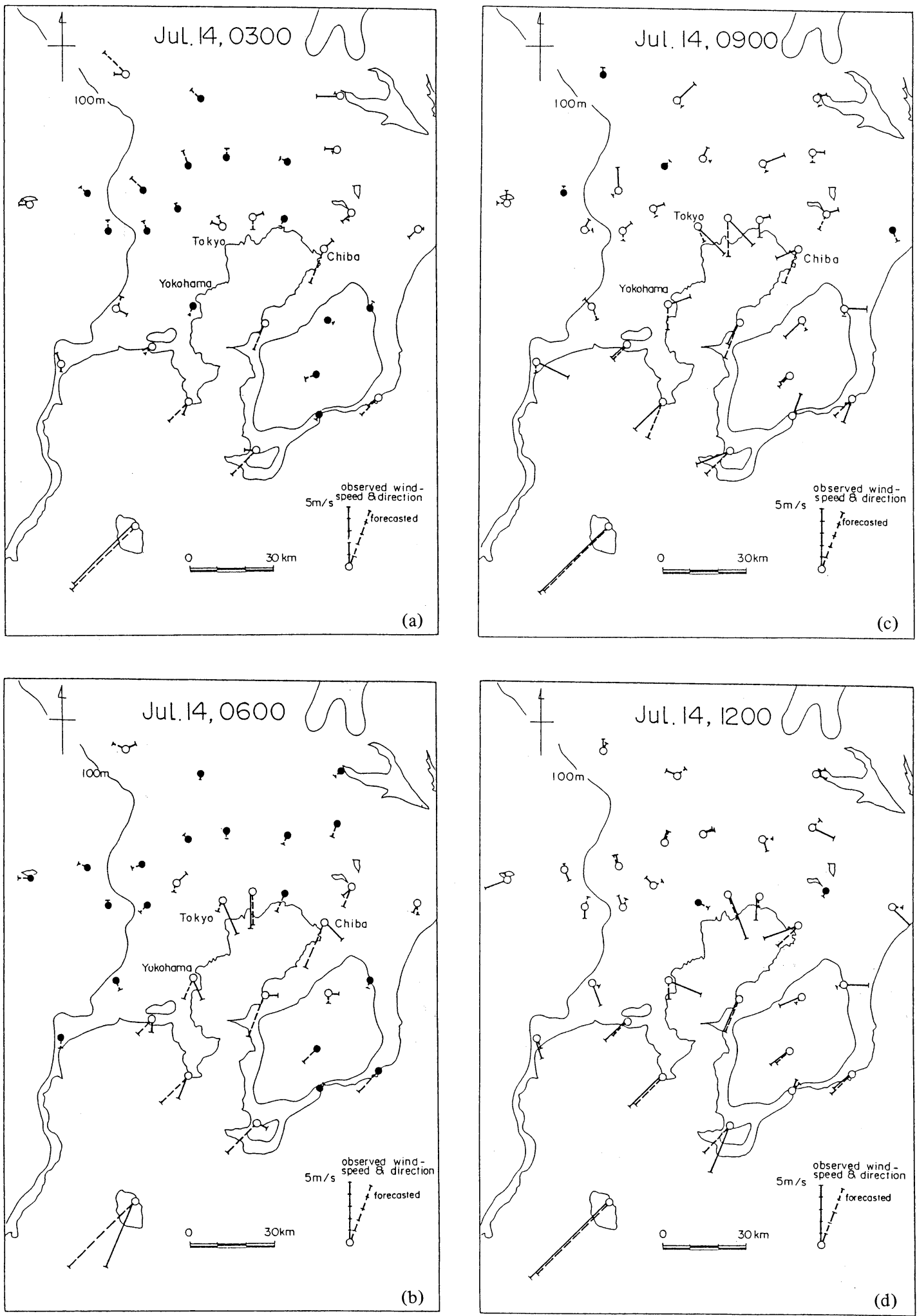


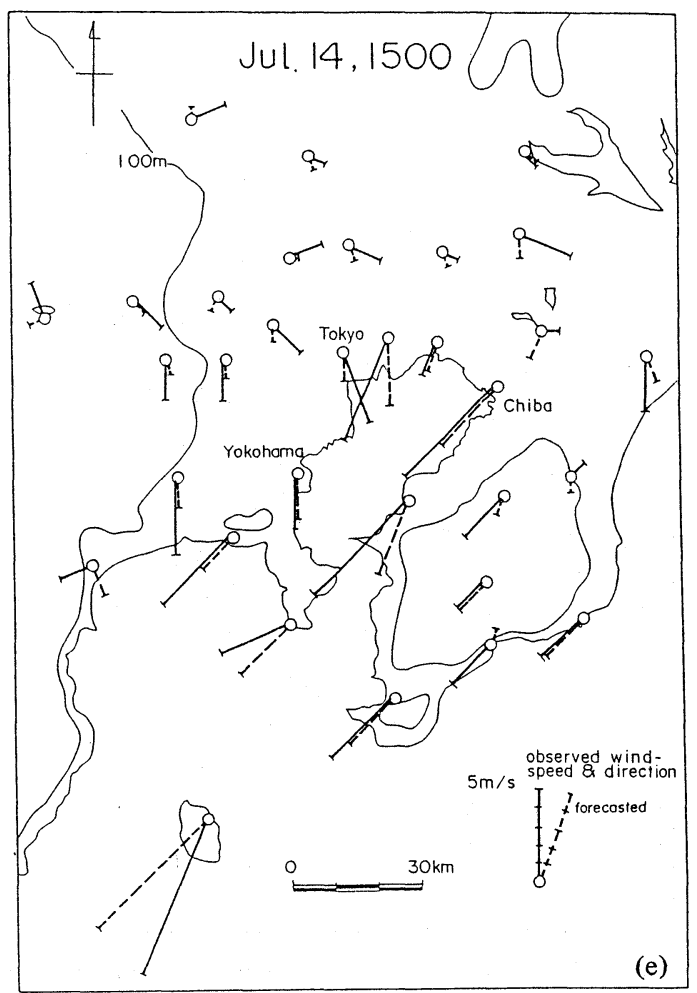

Fig. 2. Time variation of the $3 \mathrm{hr}$-forecast wind and the observed wind for 0300 JST (a), 0600 JST (b), 0900 JST (c), 1200 JST (d) and 1500 JST (e), 14 July. Solid circle indicates calm condition.

casted principal components by applying the inverse trasnsformation. Figure 2 shows the forecasted wind vectors and corresponding observed wind vectors for the forecasting time $\Delta t=3 \mathrm{hrs}$. The figure shows the temporal variations during the period from 0300 to 1500 (JST) on July 14. The observed wind data showed that it was calm everywhere in the Kanto Plain during the night and wind speed increases from dawn to daytime throughout the area. The dominant wind directions were SW near the coast and S or SE in the northern area. Figures 3 and 4 show the comparison between the observed wind and the forecasted and observed wind directions represented in 16 compass points, stratified by observed wind speed ranks; same, different by one point, different by two points, and the case when the observed wind was calm. When the observed wind speed was high, there was a good agreement. When the observed wind speed was low,

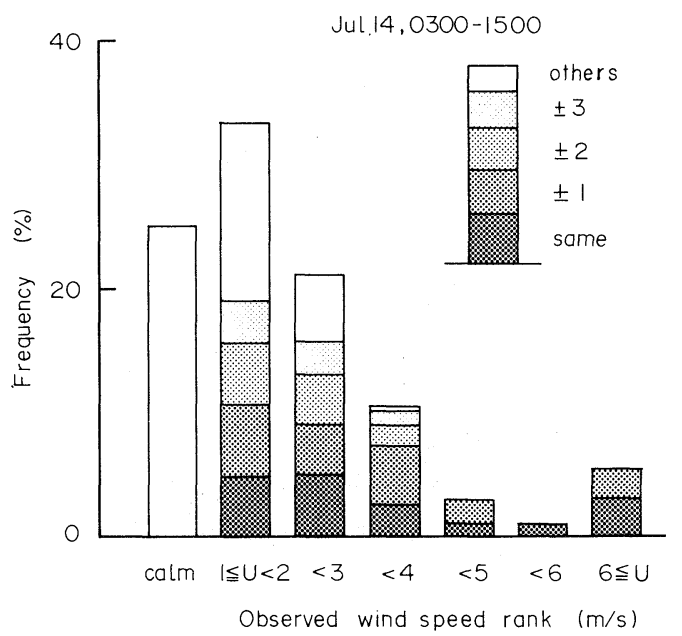

Fig. 3. Comparison of wind directions for observed wind speed ranks.

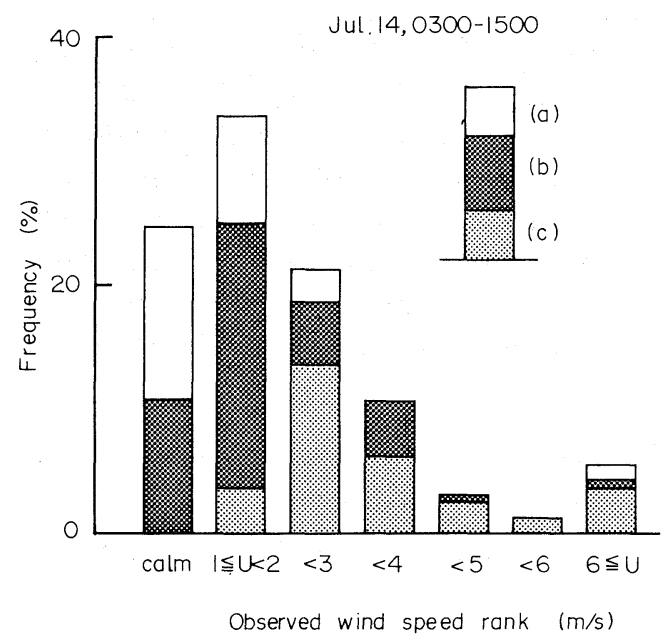

Fig. 4. Accuracy of wind speed; (a) forecasted wind speed rank was greater than, (b) equal, (c) less than that observed.

the frequency of the same wind direction was relatively low. Fig. 4 shows the agreement for wind speed. When the observed wind speed was low, the forecasted and observed wind speeds agreed well. There was, however, a tendency for the forecasted wind speed to be lower than the observed wind speed when high wind speeds were observed.

By varying the forecasting time $\Delta t$, the agreement of the directions between the forecasted and the observed wind was examined for the period from July 1 to Aug. 31 of 1981 . Figure 5 shows the agreement for all wind 


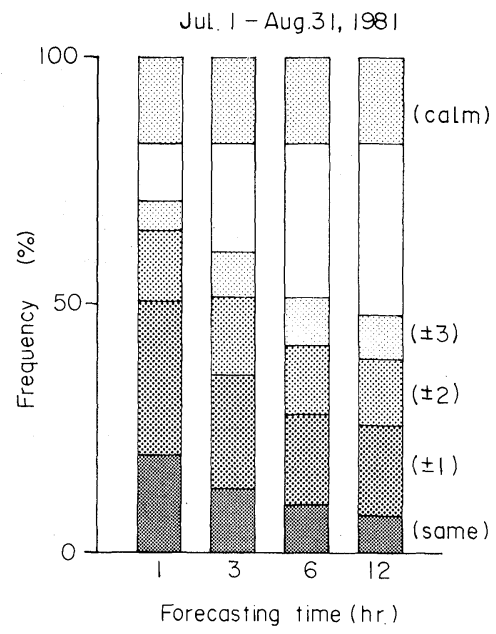

Fig. 5. Dependency of accuracy of wind directions on forecasting time.

speed ranks when $\Delta t$ is $1,3,6$ and $12 \mathrm{hrs}$. In the case of $\Delta t=3$ hours, the proportion of calm periods was about $18 \%$ of the total. Differences within \pm 2 points were about $51 \%$ of the total. The proportion of cases when forecasted and observed wind directions corresponded within \pm 3 points was always greater than the proportion of cases both directions differed by more than \pm 3 points when $\Delta t$ was less than 12 hours.

\section{Investigation of the model using vector correlation coefficient}

The forecasted wind agreed well with the observed wind as described above. The model was then evaluated by comparison with another model by using the vector correlation coefficient as the decision parameter. For the comparative model, a simple model was considered, i.e., the wind observed at a certain time treated as the forecasted wind. The vector correlation coefficient $R$ as the parameter of the degree of agreement was defined as follows,

$$
R=\frac{\sum_{i=1}^{n} V_{0 i} \cdot V_{\tau i} \cos \theta_{i}}{\sum_{i=1}^{n} V_{0 i} \cdot V_{\tau i}},
$$

where $V_{0}$; observed wind speed

$V_{\tau} ;$ forecasted wind speed

$\theta ; \quad$ angle of difference between observed and foreasted wind directions,

$n$; data number.

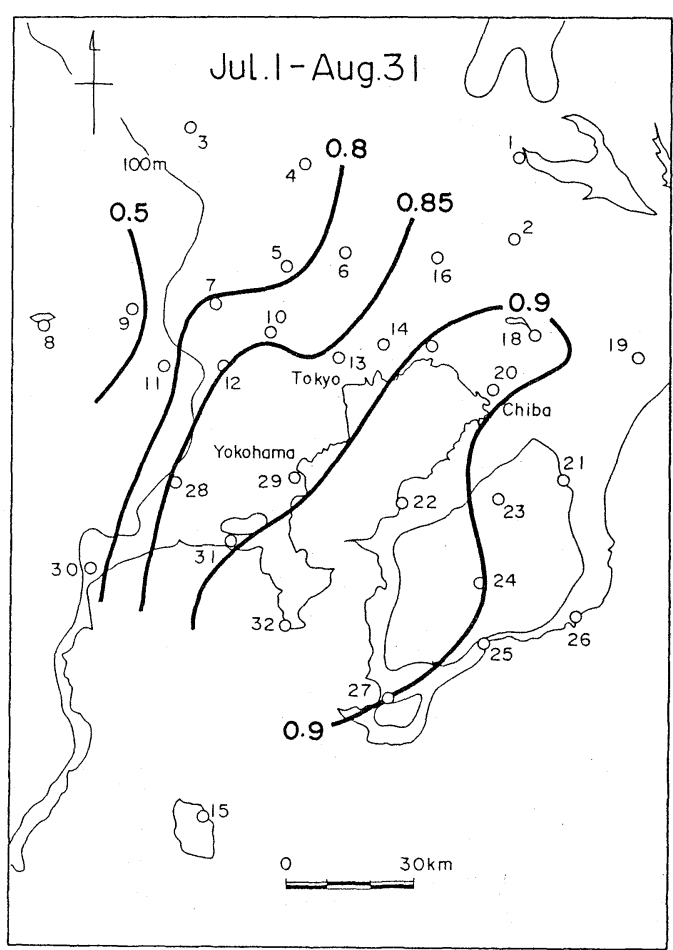

Fig. 6. Distribution of the vector correlation coefficient.

\subsection{Spatial distribution of the vector correla- tion coefficient}

The spatial distribution of the vector correlation coefficient $R$ from the proposed model was examined prior to the evaluation of the model. Figure 6 shows the distribution of $R$ for $\Delta t=$ 3 hrs. from July 1, 1981 to Aug. 31, 1981. Coefficient $R$ was relatively low at the edge of the area under study. The lower forecasting performance was probably caused by the wind correlation between the edge and the other areas being lower than that between the center and the other areas, since PCA is based on the correlation of the data. The $R$ values on the west side were especially low, and probably was the effect of the local terrain because the stations were near or among mountains. For example, station No. 8 was located in mountains higher than $1500 \mathrm{~m}$. Comparison between the forecast and observed wind was thus performed excluding stations Nos. 1, 3, 4, 8, 9 and 30 that were located at the edge. However these stations were used for developing the forecasts. 


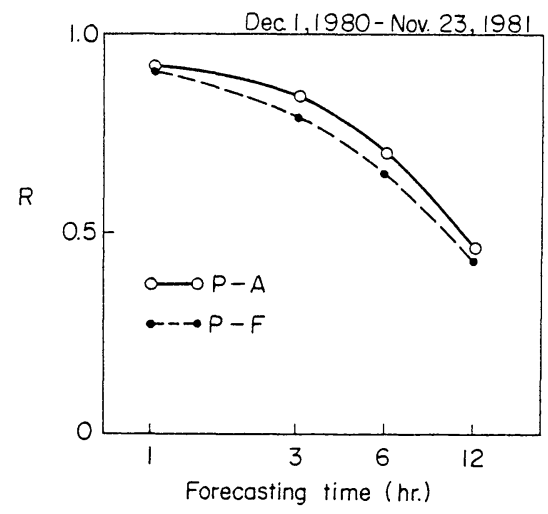

Fig. 7. Vector correlation coefficients of the P-A model and the P-F model.

\subsection{Comparison of the vector correlation co- efficient}

The evaluation of the model with the vector correlation coefficient was conducted for the period of one year from Dec. 1, 1980 to Nov. 23,1981 . The results are in Figure 7 where the vector correlation $R_{P A}$ is derived by this model (P-A model) and the vector correlation $R_{P F}$ derived by an persistence forecasting model (P-F model) using observed values before $\Delta t$ instead of the forecast values in Eq. (8) for each forecasting time of $1,3, \ldots, 12 \mathrm{hrs}$. When forecasting time was $\Delta t=1 \mathrm{hr}$., the difference between $R_{P A}$ and $R_{P F}$ is small, but as $\Delta t$ becomes longer, $R_{P A}$ becomes greater than $R_{P F}$. That is, the P-A model forecasts the wind better than the model that simply assumed the present wind continues in the future. The above comparisons were the results of calculation using all principal components, $m=2 p$, in Eq. (1). Next, another case was studied using fewer principal components than the number of stations, i.e., $m<2 p$. The accumulated proportion of the principal components for the total fluctuation changes relatively little for each calculation of eigenvector and generally the first and second principal components account for $60 \%$ of the total fluctuation. Then, another vector correlation $R_{P A}^{\prime}$ was calculated by the same method using the principal components that represented $80 \%$ of the total data fluctuations. In the latter, the number of the components was about 10 .

The results showed that $R_{P A}$ and $R_{P A}^{\prime}$ were nearly equal, e.g., in the case of $\Delta t=3$ hrs., the correlation coefficient was 0.810 using all principal components and 0.809 using fewer components which represented $80 \%$ of the fluctuation. The difference is negligible. These results show that there is no need to use all principal components, which is characteristic of PCA. That is, fewer principal components than the number of observed variables can effectively represent whole variable properties.

\section{Conclusions}

The forecasting method of wind system by a model combining principal component analysis and autoregressive equations with the maximum entropy method was able to give satisfactory future wind values. Forecasted and observed wind data agreed well when the observed wind speed was relatively high. Agreement deteriorated when the observed wind speed in the entire forecasting area was low, causing scattering of wind directions in that area. When the forecasting time was less than 12 hours and the cases when the wind was calm were excluded, the agreement between the forecasted and observed wind directions being less than \pm 3 points was always greater for this forecasting model than the persistence forecasting model.

Since, the wind data used in this paper were extracted from the AMeDAS which gives hourly data and the wind speed is represented by the unit of $1 \mathrm{~m} / \mathrm{s}$, it may be too coarse to represent rapidly changing wind systems such as accompanying the passing of fronts. The next step in this work will be to assess the sampling time and the accuracy of wind data needed to adapt this model to the rapidly changing case. Because of the lower forecasting performance at the edge of the subject area mentioned previously, the number of additional stations around the forecasting area necessary for the model to produce reasonable results must be assessed.

\section{Acknowledgement}

The authors wish to express their sincere thanks to Dr. M. Hirose for his helpful comments. 


\section{References}

Akaike, H., 1969a: Fitting autoregressive models for prediction. Ann. Inst. Statist. Math., 21, 243-247. , 1969b: Power spectrum estimation through autoregressive model fitting. Ann. Inst. Statist. Math., 21, 407-419.

Akiyama, T., 1981: Time and special variations of heavy snowfalls in the Japan Sea coastal region. J. Met. Soc. Japan, 59, 578-590.

Andersen, N., 1974: On the calculation of filter coefficients for maximum entropy spectral analysis. Geophysics, 39, 69-72.
Hardy, D.M. and J.J. Walton, 1978: Principal components analysis of vector wind measurements. $J$. Appl. Meteor., 17, 1153-1162.

Hirose, M., 1977: An investigation of the forecasting method for the regional scale weather concerning the air pollution (in Japanese), APMS, Japan Society for the Promotion of Machine Industry.

Stidd, C.K., 1967: The use of eigenvectors for climatic estimates. J. Appl. Meteor., 6, 255-264.

Ulrych, T.J. and T.N. Bishop, 1975: Maximum entropy spectral analysis and autoregressive decomposition. Rev. Geophys. Space Phys., 13, 183-200.

\title{
主成分自己回帰モデルによる地表風系の予測
}

\author{
小林博和・西宮 昌 \\ ( (財)電力中央研究所 $)$
}

地表近くで大気中に放出された污染質の挙動を解析し影響を評価するために，地表風系の統計的な子 測手法を開発した。地表風系が多数の観測点で観測された風デー夕により与えられるとすると，個々に 測定された風は互いにばらついていこも，地表風系全体では，上り大きいスケールの大気の運動に支配 されていると考えられる。そこで次のような手順により風系を予測した。はじめに主成分分析手法を用 いて, 地表風系の変動の主成分を抽出する。次にこの時系列に最大エントロピ一法を用いた自己回帰 式を適用して主成分の予測を行い，これから地表風系の予測值を得る。AMeDASの風デー夕を用いて， この手法を関東平野を対象に適用してみた。予測時間は $1 ， 3 ， 6 ， 12$ 時間とした。本手法を, 現在の 風が将来も続くとした単純なモデルと比較したところ, 本手法の方が全ての予測時間でよい予测值を与 えた。 